\title{
First Report of Treatment of Chronic Lymphocytic Leukemia in a Patient With Cystic Fibrosis
}

\author{
Abi Vijenthira ${ }^{\mathrm{a}}$, Martina Trinkaus ${ }^{\mathrm{a}, \mathrm{b}, \mathrm{c}}$
}

\begin{abstract}
Patients with cystic fibrosis (CF) are known to have an increased risk of developing hematological malignancies. Despite this, there is a paucity of evidence to guide treatment decisions in this population, which requires special consideration due to patients' risk of developing infection and baseline relative immunosuppression. There are 11 prior published reports of treatment of hematological malignancy in $\mathrm{CF}$, and no reports of treatment of chronic lymphocytic leukemia (CLL). We report the first case of treatment of CLL in a 51-year-old male with $\mathrm{CF}$. He was successfully treated with bendamustine concomitantly with prophylactic antibiotics, antifungals, and intravenous immunoglobulin (IVIG). He obtained a complete remission (CR) without any infectious complications. Following this, he relapsed and was treated to near CR with ibrutinib and monthly IVIG, with manageable infectious complications. We have shared this case with a view to contribute to the literature in this area. In particular, we have demonstrated that achieving CR in CLL without infectious complications is possible using bendamustine monotherapy, prophylactic antibiotics, and IVIG. Second, we have showed that achieving significant response with manageable infectious complications is possible with ibrutinib monotherapy and monthly IVIG.
\end{abstract}

Keywords: Cystic fibrosis; Chronic lymphocytic leukemia; Bendamustine; Ibrutinib

\section{Introduction}

Improvements in the management of patients with cystic fibrosis $(\mathrm{CF})$ over the last few decades have resulted in markedly improved survival, with most patients now living into adulthood. A consequence of this improved lifespan is an increase

\footnotetext{
Manuscript accepted for publication December 01, 2016

aniversity of Toronto, Toronto, ON, Canada

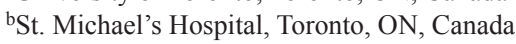

'Corresponding Author: Martina Trinkaus, St. Michael's Hospital, Room

2-084, 30 Bond Street, Toronto, ON M5W 1W8, Canada.

Email:TrinkausMa@smh.ca
}

doi: https://doi.org/10.14740/jmc2708w in patients suffering from a number of comorbidities, including malignancies.

It is well known that the risk of malignant disease increases with age in healthy populations. Patients with CF however are known to have an increased relative risk of developing certain cancers, such as gastrointestinal cancers, lymphoma, and leukemia $[1,2]$. The standardized incidence ratio has been reported as up to 7.3 for lymphoma and 2.0 for leukemias $[1,2]$.

Despite this increased risk of hematological malignancies, there is a paucity of evidence to guide treatment decisions in this population which requires special consideration due to patients' risk of developing infection and the baseline relative immunosuppression inherent in CF. Not surprisingly, this patient population is excluded from clinical trials. A review of the literature demonstrated 11 prior case reports of 15 patients with $\mathrm{CF}$ and concomitant hematological malignancies [3-13]. In these cases, six of 15 patients died, and most were reported between 1969 and 1993 when treatment differed from current protocols. Two cases involving patients with large cell anaplastic T-cell lymphoma and Hodgkin lymphoma mentioned the use of prophylactic antibiotic therapy to guard against infection during the period of immunosuppression with chemotherapy. There were no reports of treatment of chronic lymphocytic leukemia (CLL).

\section{Case Report}

We report the first case of treatment of CLL in a patient with CF. This patient was successfully treated with bendamustine chemotherapy concomitantly with prophylactic antibiotics, antifungals, and intravenous immunoglobulin (IVIG). He obtained a complete remission (CR) without any infectious complications. Following this, he relapsed and was treated to near CR with ibrutinib and monthly IVIG, with manageable infectious complications.

The patient was a 51-year-old male with CF (delta F508 and $\mathrm{R} 117 \mathrm{H}$ mutations, 5T allele) diagnosed at the age of 1 . His disease course in childhood was asthma-like and he was discharged from CF follow-up until the age of 45 when he had an empyema prompting re-referral to a CF clinic. From a CF perspective, he was colonized with Staphylococcus aureus and Burkholderia multivorans, and had pancreatic insufficiency. He had CF pulmonary exacerbations one to two times per year treated on an outpatient basis with antibiotics. His FEV1 at 
Table 1. Treatment Protocol

\begin{tabular}{|c|c|c|}
\hline Cycle & Therapy & Complications \\
\hline \multicolumn{3}{|c|}{ Treatment course 1: August 2013 - January 2014} \\
\hline 1 & $\begin{array}{l}\text { Bendamustine } 100 \mathrm{mg} / \mathrm{m}^{2}(25 \% \text { dose }) \times 2 \text { days } \\
\text { IVIG } 400 \mathrm{mg} / \mathrm{kg} \text { prophylaxis } \\
\text { Acyclovir prophylaxis } \\
\text { Septra DS tab M/W/F prophylaxis }\end{array}$ & Renal dysfunction from acyclovir therefore discontinued \\
\hline 2 & $\begin{array}{l}\text { Bendamustine }(50 \% \text { dose }) \times 2 \text { days } \\
\text { IVIG } 400 \mathrm{mg} / \mathrm{kg} \\
\text { Septra DS tab M/W/F }\end{array}$ & \\
\hline 3 & $\begin{array}{l}\text { Bendamustine }(70 \% \text { dose }) \times 2 \text { days } \\
\text { IVIG } 400 \mathrm{mg} / \mathrm{kg} \\
\text { Septra DS tab M/W/F }\end{array}$ & \\
\hline 4 & $\begin{array}{l}\text { Bendamustine }(70 \% \text { dose }) \times 2 \text { days } \\
\text { IVIG } 400 \mathrm{mg} / \mathrm{kg} \\
\text { Septra DS tab M/W/F }\end{array}$ & \\
\hline 6 & $\begin{array}{l}\text { Bendamustine }(100 \% \text { dose }) \times 2 \text { days } \\
\text { IVIG } 400 \mathrm{mg} / \mathrm{kg} \\
\text { Septra DS tab M/W/F }\end{array}$ & \\
\hline \multicolumn{3}{|c|}{ Treatment course 2: February 2015 - present } \\
\hline- & $\begin{array}{l}\text { Ibrutinib } 420 \mathrm{mg} \text { daily } \\
\text { IVIG } 400 \mathrm{mg} / \mathrm{kg} \text { monthly }\end{array}$ & $\begin{array}{l}\text { March 2015: Ascending cholangitis, Enterococcus bacteremia requiring hospital } \\
\text { admission and IV piperacillin-tazobactam. Biliary stricture NYD requiring } \\
\text { stenting. } \\
\text { April 2015: respiratory symptoms responding to a } 2 \text {-week course of doxycycline }\end{array}$ \\
\hline
\end{tabular}

time of presentation was $1.95 \mathrm{~L}$ ( $50 \%$ of expected). Functionally he was not limited. Other medical history included prior hepatitis A infection, chronic sinusitis, cholecystectomy, tonsillectomy, hernia repair, laparoscopic knee arthroscopy, and septoplasty. Medications included symbicort, ventolin, propecia, pancrelipase, and omeprazole. His family history was positive for a brother who passed away from testicular cancer.

He was referred to hematology after incidental lymphocytosis was identified on bloodwork in September 2010. At time of assessment in January 2011, he had no constitutional symptoms or history suggestive of cytopenias. His physical exam demonstrated a palpable liver and spleen $1 \mathrm{~cm}$ below the costal margin, and a $1 \mathrm{~cm}$ lymph node in the left axilla. His initial laboratory tests demonstrated a hemoglobin of $133 \mathrm{~g} / \mathrm{L}$, white blood cell count of $48 \times 10^{9} / \mathrm{L}$ with a lymphocyte count of 39 $\times 10^{9} / \mathrm{L}$, and a platelet count of $141 \times 10^{9} / \mathrm{L}$. Creatinine was $86 \mu \mathrm{mol} / \mathrm{L}$. Serum protein electrophoresis was normal. He had hypogammaglobulinemia with an IgG count of $7.14 \mathrm{~g} / \mathrm{L}$. Flow cytometry confirmed a diagnosis of CLL with $92 \%$ monoclonal B cells positive for CD19, 20, 22, 23, 5, kappa restricted, and negative for CD38. Cytogenetics demonstrated 13q deletion homozygosity, and were negative for the $17 \mathrm{p}$ deletion. Additional prognostic testing such as immunoglobulin variable chain mutations was not available.

The patient underwent active surveillance of his CLL and was monitored at 3-month intervals. He remained asymptomatic, with gradual growth of lymphadenopathy, one of which was biopsied and consistent with small lymphocytic lymphoma. Approximately 22 months after his original diagnosis, he developed thrombocytopenia (WBC $225 \times 10^{9} / \mathrm{L}$, Hgb 122 $\mathrm{g} / \mathrm{L}$, and Plts $\left.87 \times 10^{9} / \mathrm{L}\right)$. Beta-2 microglobulin was $3.1 \mathrm{mg} / \mathrm{L}$. FISH for the IgH/CCND1 marker was negative, thereby ruling out a CD23 mantle cell lymphoma. CT scans of the chest, abdomen, and pelvis demonstrated generalized lymphadenopathy with no conglomerate masses and a spleen size of $22 \mathrm{~cm}$.

\section{First treatment course}

With progressive symptomatic lymphadenopathy and declaration of RAI stage IV CLL treatment was initiated. His original cumulative illness rating scale score was 6 . Possible treatment regimens considered included fludarabine-based, bendamustine-based, and chlorambucil-based therapies with or without rituximab. He was excluded from clinical trials due to a history of empyema. Due to the infectious risk associated with fludarabine [14], this patient was placed on bendamustine monotherapy for six cycles. Rituximab was not given concurrently, as it was not covered with the government's or patient's private insurance plan.

With his progressive cytopenias at time of initiation of treatment $\left(\right.$ WBC $431 \times 10^{9} \mathrm{~g} / \mathrm{L}, \mathrm{Hgb} 89 \mathrm{~g} / \mathrm{L}$, and Plts $\left.38 \times 10^{9} / \mathrm{L}\right)$, the patient received six total cycles of dose-reduced bendamustine which was slowly uptitrated to full dose, prophylactic an- 
tibiotics with septra, prophylactic antivirals with acyclovir, and monthly IVIG infusions for infection prophylaxis (Table 1).

Overall, the patient tolerated his six cycles of chemotherapy well from a symptomatic and CF perspective. He had no pulmonary exacerbations during his treatment course. Restaging CT scans at the end of six cycles of treatment showed significant interval reduction in the size of his spleen and lymph nodes to $\leq 1.5 \mathrm{~cm}$. His $\mathrm{CBC}$ was normal. He achieved a CR for approximately 6 months.

\section{Second treatment course}

In January 2015, the patient presented to the hematology clinic with weight loss, night sweats, palpable lymphadenopathy, and splenomegaly. His laboratory parameters demonstrated an increased WBC $73 \times 10^{9} / \mathrm{L}$, lymphocytes $64.3 \times 10^{9} / \mathrm{L}, \mathrm{Hgb} 126$ $\mathrm{g} / \mathrm{L}$, and Plts $94 \times 10^{9} / \mathrm{L}$. Declaring himself with relapsed CLL, repeat FISH cytogenetics obtained demonstrated $13 \mathrm{q}$ deletion and a new $17 \mathrm{q}$ deletion. Repeat CT scans revealed interval increase in neck, chest, and abdominal lymphadenopathy, splenomegaly, and periportal infiltration suspicious for leukemic infiltration, which was later confirmed with ERCP brushings. A lymph node biopsy ruled out the possibility of a Richter's transformation.

With rapidly progressing CLL and a new 17p deletion clone, he was started immediately on ibrutinib monotherapy at a dose of $420 \mathrm{mg}$ daily with IVIG monthly prophylaxis. Ibrutinib is a novel brunton tyrosine kinase inhibitor currently approved for patients with refractory or relapsed CLL or those with 17 p deletion CLL [15]. Within 5 days, the patient noted decreased head and neck lymphadenopathy, and splenomegaly.

His treatment course was complicated by hospital admission in March 2015 with ascending cholangitis and enterococcus bacteremia requiring IV piperacillin-tazobactam therapy. Ibrutinib was continued during this time with all lymphadenopathy vanishing within 4 weeks of initiation.

Two months following initiation of ibrutinib in April 2015, he developed increasing green sputum and right-sided chest pain with no chest X-ray infiltrate. He was treated empirically with doxycycline to cover his known colonization with $B$. multivorans with good effect.

By April 2016, 14 months into treatment, he continued on daily ibrutinib therapy and prophylactic monthly IVIG, with a reduction in lymphocytosis, lymphadenopathy and splenomegaly, and a stable respiratory status from a CF perspective. The patient's most recent FEV1 was notably above his baseline at $2.06 \mathrm{~L}$ (56\% predicted). He has sustained no adverse events that are now recognized with ibrutinib such as atrial fibrillation, bleeding and diarrhea [16]. His most recent CT imaging 6 months following initiation of ibrutinib shows all lymph nodes measuring $<1.0 \mathrm{~cm}$ with a spleen size of $13 \mathrm{~cm}$.

\section{Discussion}

In summary, to our knowledge, this is the first report of treatment of CLL in a patient with CF. We have shared this case with a view to contribute to the literature in this area. Respirologists and hematologists are often apprehensive to treat patients with CF with chemotherapy due to their inherent immunosuppression, leading to potential delays in treatment.

In this report, we have demonstrated that achieving CR without infectious complications is possible using bendamustine monotherapy, prophylactic antibiotics, and IVIG. Second, we have shown that achieving significant response with manageable infectious complications is possible with ibrutinib monotherapy and monthly IVIG.

We believe that the information presented regarding selection of chemotherapy and prophylactic treatment will be useful to clinicians in the treatment of CLL and other hematologic malignancies.

\section{Funding Sources}

None.

\section{Conflicts of Interest}

None.

\section{References}

1. Johannesson M, Askling J, Montgomery SM, Ekbom A, Bahmanyar S. Cancer risk among patients with cystic fibrosis and their first-degree relatives. Int $\mathrm{J}$ Cancer. 2009;125(12):2953-2956.

2. Maisonneuve P, Marshall BC, Knapp EA, Lowenfels AB. Cancer risk in cystic fibrosis: a 20-year nationwide study from the United States. J Natl Cancer Inst. 2013;105(2):122-129.

3. Miller RW. Childhood cancer and congenital defects. A study of U.S. death certificates during the period 19601966. Pediatr Res. 1969;3(5):389-397.

4. Biggs BG, Vaughan W, Colombo JL, Sanger W, Purtilo DT. Cystic fibrosis complicated by acute leukemia. Cancer. 1986;57(12):2441-2443.

5. Marra R, Pagano L, Storti S, Valente S, Leone G, Bizzi B. Cystic fibrosis complicated by Hodgkin's lymphoma. Panminerva Med. 1990;32(3):149-150.

6. Rizzari C, Conter V, Jankovic M, D'Angelo P, Masera G, Costantini D, Bettinelli ME, et al. Acute lymphoblastic leukaemia in a child with cystic fibrosis. Haematologica. 1992;77(5):427-429.

7. Sheldon CD, Hodson ME, Carpenter LM, Swerdlow AJ. A cohort study of cystic fibrosis and malignancy. Br J Cancer. 1993;68(5):1025-1028.

8. Gururangan S, Horner M, Rodman JH, Marina NM. Successful treatment of acute lymphoblastic leukemia in a child with cystic fibrosis. Med Pediatr Oncol. 1994;22(6):414-416.

9. Eisen S, Painter H, Hyde SC, Davies J, Jaffe A. Clinical improvement in cystic fibrosis following anti-tumourous 
chemotherapy. Arch Dis Child. 2004;89(12):1179-1180.

10. Tschiedel E, Grasemann H, Ratjen F. Mycobacterium chelonae in a CF patient with anaplastic large cell lymphoma. J Cyst Fibros. 2006;5(2):133-136.

11. Aytac S, Pekcan S, Dogru D, Dorttepe I, Kara A, Cetin M. Cystic fibrosis with acute myelogenous leukemia. Turk J Pediatr. 2009;51(3):290-293.

12. Dopfer C, Kentouche K, Gruhn B, Dopfer R, Becker S, Mentzel HJ, Beck JF, et al. Acute lymphoblastic leukemia in a 10-year-old boy with cystic fibrosis - improvement of pulmonary function during chemotherapy in spite of intermittent Pseudomonas aeruginosa colonisation. Klin Padiatr. 2011;223(6):368-369.

13. Baumann S, Kuchler F, Reinwald M, Tenenbaum T, Hartel N, Hofmann WK, Buchheidt D. Hodgkin's lymphoma in a patient with cystic fibrosis: a clinical challenge. Ann Hematol. 2013;92(4):571-572.

14. Hallek M, Cheson BD, Catovsky D, Caligaris-Cappio F, Dighiero G, Dohner H, Hillmen P, et al. Guidelines for the diagnosis and treatment of chronic lymphocytic leukemia: a report from the International Workshop on Chronic Lymphocytic Leukemia updating the National Cancer Institute-Working Group 1996 guidelines. Blood. 2008;111(12):5446-5456.

15. Product Monograph: Imbruvica (ibrutinib). Janssen Inc. July 24, 2015.

16. Byrd JC, Brown JR, O'Brien S, Barrientos JC, Kay NE, Reddy NM, Coutre S, et al. Ibrutinib versus ofatumumab in previously treated chronic lymphoid leukemia. N Engl J Med. 2014;371(3):213-223. 